beginning of the cycle and values then rose to a maximum after ovulation (identified by the basal temperature rise in two women). This increase was similar to the rise in oestrogen production during the cycle and suggests that it is oestrogenic hormones which control the variation in glucose tolerance. Unfortunately they did not measure hormone excretion, so it is impossible to tell whether the women who had irregular variations (three out of the ten) were abnormal in their hormone production or were responding abnormally to a normal pattern of hormone production.

One factor affecting blood clotting has now been shown to be affected by oestrogens. Daniel et al. (Brit. Med. J., i, 801; 1968) found that the blood of women given stilboestrol to suppress lactation contains more Christmas factor (factor IX) than the blood of lactating women or women who are not feeding their babies but not receiving oestrogens. This result is interesting in view of the possible connexions between "the pill" and blood clotting. The multitude of different effects of oestrogens, however, makes the task of identifying their role in cardiovascular disease more complicated.

\section{Hydrobiology in Africa}

from a Correspondent

After the successful meeting of Latin American hydrobiologists held in March 1968 at Santa Fé, Argentina (Nature, 218, 417; 1968), a second regional meeting devoted to tropical hydrobiology was organized by the International Biological Programme at Makerere University College, Uganda, from May 20 to 24, 1968. Hydrobiologists from ten African countries, both French and English-speaking, attended, together with observers from France and the United Kingdom.

Although the aims of this meeting were similar to those of the Latin American meeting-contacts and stocktaking of results, problems and gaps-the results and the scene differed considerably. For at least forty years East Africa with its lakes has been the object of unceasing attention from European scientists, though less attention has been paid to the other regions. There is, therefore, an uneven state of knowledge on the inland waters of Africa. Besides reports on organization and work in progress, there were some highly advanced communications on comparative limnochemistry of East African waters, on the characteristics of waters of the Congo Basin and a detailed analysis of the explosive fish speciation in Lake Victoria. For the first time the limnological team now working on Lake Chad and organized by ORSTOM (Organization de Recherches Scientifiques et Techniques OûtreMer) appeared with preliminary reports on various aspects of this fascinating inland basin. ORSTOM maintains probably the biggest research staff of thirtyfive collaborators at its establishment at Fort Iamy (Chad).

The meeting dealt with various types of waters, both natural lakes and rivers, and the newly created manmade lakes of Kariba, Volta and Kainji, where changes of fish faunas are under way. The attendance of FAO/ UNDP workers was gratifying: their work, which is aimed at practical exploitation problems, overlaps with many fundamental issues of hydrobiology. It became clear during the course of the meeting that at least in hydrobiology/limnology, there is no exclusive delimitation between fundamental and applied knowledge.

Professor De Bont, from the Congo, pointed out that three previous African meetings, organized by intergovernmental agencies, were held in 1952, 1956 and 1959 and were devoted mainly to fishery problems, with a fringe of fundamental limnology, whereas the present meeting was mainly directed toward the latter. African limnology, judging by the presence of many Africans at the meeting, is growing fast. Consequently, recognition and collation of all previous offorts are imperative.

\section{Geometry of Gear Hobbing} from a Correspondent

Most investigators in the field of metal machining concentrate their efforts on the mechanics of the cutting process, the conditions at the tool-chip contact zone and possibly the resulting cutting forces and tool wear rates. Moreover, in order to exclude influences which may interfere with the understanding of the basic principles, studies are usually confined to orthogonal cutting conditions where, from the point of view of the process geometry, the cross-section of the chip remains constant, although-for instance-vibrations and other effects may cause chip thickness variations in practice.

In the machining operations in industry there are, however, many examples where chip thickness variations are not due to undesirable influences but to the basic geometry of the process involved. An example is the case of milling in which, even when the material to be removed is of constant depth throughout, the thickness of each chip eut during the engagement of a cutter tooth in the workpiece material varies periodically, thus causing regular and predictable cutting force pulsations. The problem becomes more complex in the gear hobbing process, when not one but several surfaces have to be simultaneously generated. Here, variations of the chip section are due not only to the basic geometry of the milling process as such but also to the geometry of hobbing, in that both the width and depth of the cuts change as the operation proceeds.

In view of the fact that the magnitude of the chip section has a direct influence on the cutting forces and the cutter wear, and that these may affect the stability of the operation and in turn the accuracy and surface quality of the machined gear teeth, the authors of a paper now circulated by the Institution of Mechanical Engineers-Mr R. G. Hannam and Mr C. Andrewhave analysed the process geometry and thus developed a means for predicting the force distribution and pulsations during hobbing operations.

The analysis was carried out by studying first the action in a plane which is perpendicular to the axis of the gear blank and at the same time contains the common perpendicular to the axes of gear blank and hob. The next step was the analysis of the cutting action in planes at right angles to the first,-in planes which are parallel to the axis of the gear blank. The results show the action of the various cutting edges, in particular the number of hob teeth engaged in forming a tooth space and the amounts of metal removed at its flanks and root.

The authors found for a specific example, calculated with the aid of a computer, that the maximum chip section removed by the tips of the hob teeth is more 